\title{
A Thiazole Analogue Exhibits an Anti-Proliferative Effect in Different Human Carcinoma Cell Lines and Its Mechanism Based on Molecular Modeling
}

\author{
Hatem K. Amin ${ }^{* *}$, Amr M. El-Araby², Sameh Eid ${ }^{3}$, Tamer Nasr ${ }^{4}$, Samir Bondock5 , Ola Leheta6, \\ Moustafa E. Dawoud ${ }^{*}+$ \\ ${ }^{1}$ Department of Biochemistry and Molecular Biology, Faculty of Pharmacy, Helwan University, Cairo, Egypt \\ ${ }^{2}$ Faculty of Pharmacy, Ain Shams University, Cairo, Egypt \\ ${ }^{3}$ Biomed X Innovation Center, Heidelberg, Germany \\ ${ }^{4}$ Department of Pharmaceutical Chemistry, Faculty of Pharmacy, Helwan University, Cairo, Egypt \\ ${ }^{5}$ Department of Chemistry, Faculty of Science, Mansoura University, Mansoura, Egypt \\ ${ }^{6}$ Department of Clinical Pathology, College of Medicine, Suez Canal University, Ismailia, Egypt \\ ${ }^{7}$ Department of Organic Pharmaceutical Chemistry, Faculty of Pharmacy, Helwan University, Cairo, Egypt \\ Email: ${ }^{*}$ hatem.k.amin@gmail.com, ${ }^{\dagger}$ alamka@gmail.com
}

How to cite this paper: Amin, H.K., El-Araby, A.M., Eid, S., Nasr, T., Bondock, S., Leheta, O. and Dawoud, M.E. (2017) A Thiazole Analogue Exhibits an Anti-Proliferative Effect in Different Human Carcinoma Cell Lines and Its Mechanism Based on Molecular Modeling. Advances in Biological Chemistry, 7, 76-87.

https://doi.org/10.4236/abc.2017.71005

Received: January 13, 2017

Accepted: February 25, 2017

Published: February 28, 2017

Copyright $\odot 2017$ by authors and Scientific Research Publishing Inc. This work is licensed under the Creative Commons Attribution International License (CC BY 4.0).

http://creativecommons.org/licenses/by/4.0/

\begin{abstract}
Purpose: Aim of this study is to assess the anti-proliferative effect of the thiazole analogue (5-acetyl-4-methyl-2-(3-pyridyl) thiazole) with different human carcinoma cell lines and to postulate its possible mechanism of action using molecular modeling. Methods: Three different human carcinoma cell lines were used namely hepatocyte carcinoma (HEPG2), breast adenocarcinoma (MCF7) and colon cancer (HCT116). Molecular docking simulations for tested thiazole analogue and its virtual analogues against the cytochrome P-450 2A6 enzyme and mutated SOD were performed. Results: Cell lines cytotoxicity revealed that the tested thiazole analogue exerts a significant anti-proliferative activity in all the used human carcinoma cell lines with a pronounced anti-proliferative effect in liver carcinoma cell line HEPG2 $\left(\mathrm{IC}_{50}=\right.$ $23.8 \mu \mathrm{g} / \mathrm{ml}$ ) whereas the anti-proliferative effect in colon carcinoma and breast cancer cell lines was poor with $\mathrm{IC}_{50}=50 \mu \mathrm{g} / \mathrm{ml}$ and $\mathrm{IC}_{50}>50 \mu \mathrm{g} / \mathrm{ml}$ respectively. The postulated mechanism of action revealed the high affinity to inhibit SOD and CYP2A6 enzymes in the liver. Conclusion: The thiazole analogue (5-acetyl-4-methyl-2-(3-pyridyl)thiazole) is a potential liver specific anticancer agent capable of interfering with both apoptotic signaling pathway and the free radical processing in liver which leads to more studies on liver cancer from different perspective rather than the apoptotic signaling pathway.
\end{abstract}




\section{Keywords}

Thiazole, Liver Cancer, Hepatocyte Carcinoma, Breast Adenocarcinoma, Colon Cancer, Molecular Docking, Superoxide Dismutase, CYP2A6

\section{Introduction}

Cancer has become the leading disease-related cause of deaths of humans [1]. Radiation therapy and surgery treatments are only successful when cancer is localized in the early stage whereas chemotherapy has the ability to cure widespread or metastatic cancers. Approximately $74 \%$ of anti-cancer drugs are either natural products, semi synthetic compounds or their mimetics [2]. Inhibition of hemoproteins such as cytochromes $\mathrm{P} 450$ is a widely pursued area of research for cancer treatment and prevention [3]. CYP proteins in general have about 500 amino acid residues with 2 main domains: the $\alpha$-domain (13 $\alpha$-helices) and the $\beta$-domain (5 $\beta$-sheets). The $\alpha$-domain contains the heme binding pocket and $\beta$-domain has the $\mathrm{N}$-terminus [4]. The enzyme compact structure stability is due to phenylalanine residues (Phe107, Phe111, Phe118, Phe209 and Phe480) located above the haem to form the upper surface of the enzyme active site pocket. The $\pi-\pi$ stacking because of the aromatic residues leads to the formation of a hydrogen bond with the ligands, such as methoxsalen, coumarin and amine derivatives due to the interaction with Asn297 residue and aromatic ligands [5] [6].

Humans have CYP2A gene cluster in chromosome 19 which contains the three functional genes, CYP2A6, CYP2A7 and CYP2A13 [7].

In human liver, cytochrome P450 2A6 (CYP2A6) constitutes up to $10 \%$ of the total P450 content. The human CYP2A6 is expressed in the endoplasmic reticulum of hepatocytes in the liver, oesophagus, lung, trachea, nasal mucosa, and skin [8].

CYP2A6 as catalysts of bilirubin oxidation suggest a role in haem homeostasis and in the regulation of cellular redox balance [9]. CYP2A6 hepatic over expression is elevated in hepatocellular carcinoma associated with cirrhosis and chronic inflammation [10]. Inhibition of CYP2A by chalepensin causes cytotoxicity in carcinoma cell lines and this might have significance in target organs expressing CYP2A6, like testis, ovary, uterus and liver [11].

The first identified SOD was erythrocuprein [12]. $\mathrm{Cu}, \mathrm{Zn}$ superoxide dismutases ( $\mathrm{Cu}, \mathrm{Zn}$-SODs) are metallo-enzymes involved in cellular defense mechanism against oxidative damage. Eukaryotic $\mathrm{Cu}, \mathrm{Zn}$-SODs are homodimers with one atom of both zinc and copper per subunit and catalyze the superoxide anion dismutation at a diffusion-limited rate enhanced by electrostatic guidance of the substrate to the active site [13].

The oxidized form of $\mathrm{Cu}, \mathrm{Zn}$-SOD active site has a $\mathrm{Cu}$ ion coordinated in a distorted square pyramid by a solvent molecule and four histidines, one His is also a ligand to a tetrahedral $\mathrm{Zn}$ coordinated by two other His and an Asp [14]. Local positive charge attracts a series of small anions that bind directly to $\mathrm{Cu}$ in 
place of the solvent molecule then extend in the direction of the conserved Arg143 [15]. In reduction status, $\mathrm{Cu}$ is thought to release the His63 ligand it shared with the $\mathrm{Zn}$ ion and departing $\mathrm{O} 2$, to allow its conformation to become trigonal and roughly planar. Fe-SOD and Mn-SOD upon reduction, the active site electrostatics are conserved overall by uptake of a proton [16].

In tumor cells, several observations suggesting that ROS may mediate apoptosis, thus depletion of endogenous antioxidants can promote apoptosis, and presence of endogenous antioxidants can sometimes delay or inhibit apoptosis [17] suggesting that the use of anti-SOD may be of significance as an anti-cancer drug [18].

Thiazoles are a familiar group of heterocyclic compounds have a wide variety of biological activities [19] such as treatment of pain [20], inflammation, HIV infections [21], bacterial infection [22], anti-tubercular [23], and inhibitors of bacterial DNA gyrase B [24]. Thiazole antibiotics Siomycin A [25] and thiostrepton [26] inhibit FoxM1 and induce apoptosis in human cancer cells; therefore thiazole derivatives developed as potential anticancer agents [27], and have been reported to display anti-proliferative activity.

From the above mentioned literature, we aim to assess the anti-proliferative effect of the thiazole analogue [5-acetyl-4-methyl-2-(3-pyridyl) thiazole] with different cell lines (liver, breast, and colon) carcinoma and to postulate its possible mechanism of action.

\section{Experimental}

\subsection{Thiazole Analogue Preparation and Chemicals}

The tested thiazole analogue-acetyl-4-methyl-2-(2-pyridyl) thiazole was synthesized according to reported scheme by Bondok et al. [28] without any change and all the used chemicals were purchased from Sigma-Aldrich (USA), Merck $\mathrm{KGaA}$ (Germany) and Structure confirmation using melting point and $1 \mathrm{H}$ NMR was found identical to literature.

\subsection{Cell Lines Cytotoxicity Protocol}

Three different human cell lines were used namely hepatocyte carcinoma (HEPG2), breast adenocarcinoma (MCF7) and colon cancer (HCT116). All the cell lines, the used reagents and staining dyes were from Sigma Aldrich (USA).

Cell lines cytotoxicity protocol according to Skehan et al. [29] Cells were plated in 96 multi well plate ( 104 cells/well) for 24 hours before the addition of the tested thiazole analogue to allow attachment of the cells to the plate wall. Different concentrations of the tested thiazole analogue $(0,5,12.5,25,50 \mu \mathrm{g} / \mathrm{ml})$ were added to the cell monolayer triplicate wells. Monolayer cells were incubated with the compound for 48 hours at $37 \mathrm{C} 0$ and in atmosphere of $5 \% \mathrm{CO}_{2}$. After 48 hours cells were fixed, washed and stained with Sulfo-Rhodamine-B stain. Washing the excess stain by acetic acid and attached stain was recovered with Tris-EDTA buffer. ELISA reader was used to measure color intensity and the relation between surviving fraction and drug concentration is plotted to get 
the survival curve of each tumor cell line.

\subsection{Docking Studies of the Thiazole Analogue against SOD and CYP2A6}

Docking studies were performed using Sybyl-X molecular modelling program. Sybyl-X uses the Surflex Docker which performs its molecular docking function aided by the generation of an idealized active site (Protomol) consisting of dummy atoms to guide the docking process. The Protomol is generated based on the interaction between the indigenous ligand and the active site residues is located beyond the co-crystallized ligand pocket for best accuracy. The crystal structures of SOD and CYP2A6 were both download from the RCSB website (www.rcsb.com) (PDB Codes: 2WZ6 and 2FDW respectively). All mutations present in the structure were mutated back to the wild type protein. The metal ions and metal-ligand bonds were defined and appropriate charges were assigned to avoid repulsion between the test ligand and metal ions. The proteins were then prepared for docking using the Biopolymer Preparation tool according to the following criteria: H-Addition, H-Bond; Termini treatment, charged; Protonation type of histidines, according to H-Bonding donor or acceptor; Side Chain Bumps, Fix by Lovell method. At the end of the preparation, brief Staged Energy Minimization was performed to the amino acid residues only using the following parameters: Iterations, 100; Initial Minimization, None; Force Field, MMFF94s; Charges, MMFF94; Dielectric constant, Constant; Non-Bonding Cutoff, $8.0 \AA$. The prepared proteins were saved as a MOL2 files. The ligands were then generated using ACD/Chemsketch software (appreciably available for free downloading by ACD Labs, Inc.) and saved in SD format. The 3D structures were generated by Concord protocol of Sybyl-X and saved as SLN files to be used for docking. Docking was performed using the Dock Ligands protocol of Sybyl-X. The protomol was generated using the co-crystallized ligand of each protein. The docked ligands were then inspected to compare the similarities and differences in binding modes with the co-crystallized ligands.

\section{Results and Discussion}

Performance of cytotoxicity tests has shown that the tested thiazole analogue 5-acetyl-4-methyl-2-(3-pyridyl) thiazole demonstrates considerable cytotoxicity against all used cell lines. The compound has shown prominent cytotoxic selectivity towards hepatocellular cancer (HEPG2) cell line with and IC50 of 23.8 $\mu \mathrm{g} / \mathrm{ml}$. This potency is considerably much lower than the cytotoxic potencies of the compound against colorectal cancer (HCT116) and breast adenocarcinoma (MCF7) cell lines were the IC50 values were $50 \mu \mathrm{g} / \mathrm{ml}$ and $>50 \mu \mathrm{g} / \mathrm{ml}$ respectively (Figure 1).

This selective property of the compound may be attributed to the proposed mechanism of action. We conducted structure similarity search studies to identify possible biochemical targets of the tested compound. The search showed that our compound exhibited appreciable structure similarity with inhibitors of the 
superoxide dismutase [30] (SOD) and cytochrome P450 2A6 (CYP2A6) [5] (Figure 2). This is consistent with the cytotoxicity assay results since SOD and CYP2A6 are much more abundant in the liver tissue [31]. Molecular docking studies were performed to study the binding interactions between the studied compound and the postulated biochemical targets and compare the predicted binding modes with the ligands in the co-crystal structure.

SOD are essential enzymes to protect cells from damage induced by superoxide radical (O2-) [32]. The active O2-production and low SOD activity in cancer cells [33] [34] [35] may render the malignant cells survival highly dependent on SOD levels consequently SOD inhibition would promote cancer cell deathcancer cells death. Mitochondria are the major source of superoxide production and inhibition of SOD causes mitochondrial membrane damage through free-radical
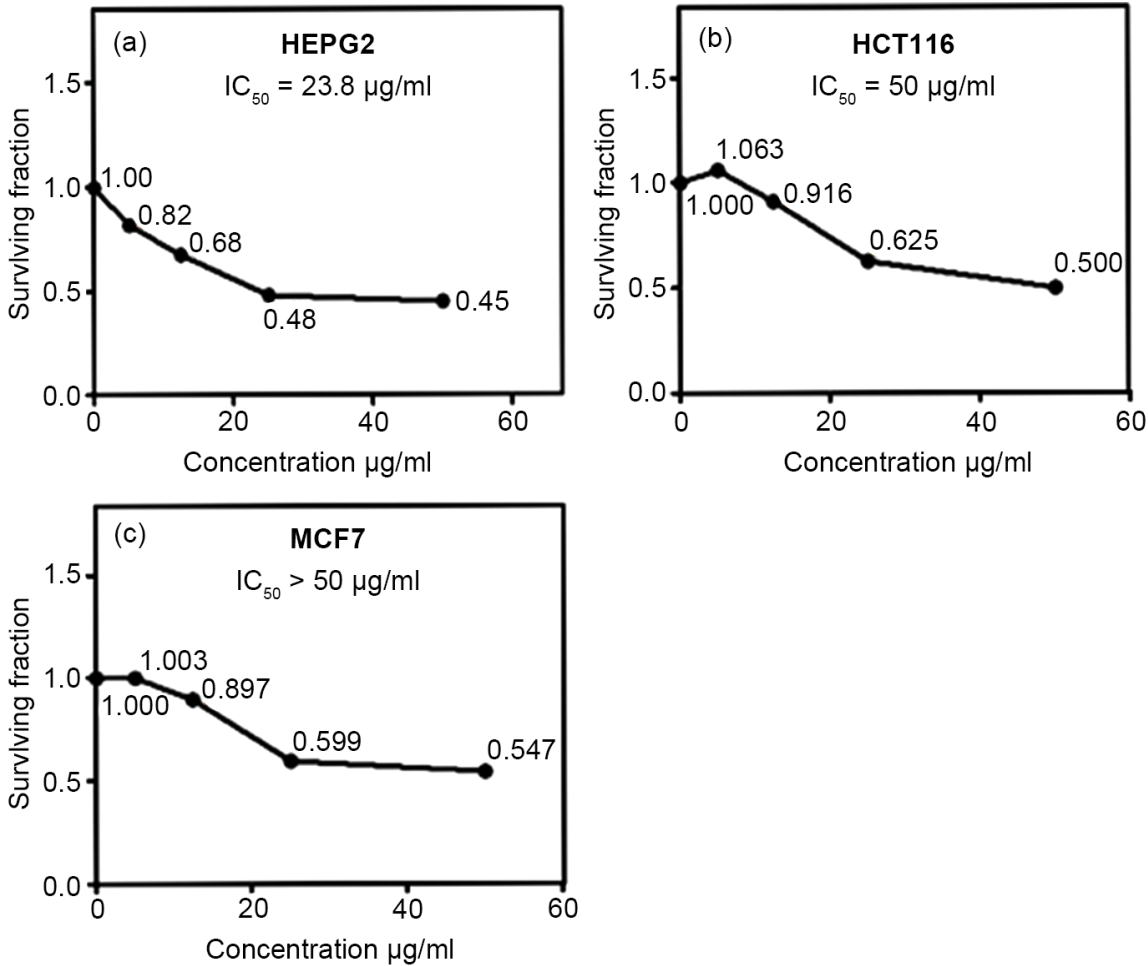

Figure 1. The concentration-activity curves of the tested thiazole compound expressed as fraction of surviving cells against compound concentration for different cell lines; liver carcinoma (HEPG2) (a), colon carcinoma (HCT116) (b) and breast adenocarcinoma (c).<smiles>CC(=O)c1sc(-c2cccnc2)nc1C</smiles>

(1)<smiles>FC(F)(F)c1nc(N2CCCNCC2)c2ccccc2n1</smiles>

(2, PDB: 2WZ6)<smiles>NCc1ccc(-c2cccnc2)o1</smiles>

(3, PDB: 2FDW)

Figure 2. The structures of the tested thiazole compound (1), SOD quinazoline inhibitor (Hasnain et al. 2010) (2) and CYP2A6 inhibitor (Cashman et al. 2006). 
attack on membrane phospholipids and loss of the ability to retain a fluorescent dye (rhodamine-123) used to indicate the loss of mitochondrial transmembrane potential [36] [37]. Damage to phospholipids results in the release of mitochondrial cytochrome $c$ to the cytosol triggering apoptosis [38]. SOD inhibition might have different mechanisms such as inhibition of tubulin polymerization and angiogenesis [39] [40].

SOD enzyme crystal structure reveals a catalytic site which can bind metal chelators principally due to the presence of metal cations [14]. Hasnain et al. [41], however, discovered an allosteric site that binds 2-trifluormethyl-4-quinazoline derivatives as inhibitors of $\mathrm{Cu}-\mathrm{Zn}$ loaded SOD. Molecular docking studies revealed several similarities between the binding modes of the tested thiazole and Hasnain's 2-trifluormethyl-4-quinazoline derivative. Hasnain et al. [41] demonstrated that the trifluromethyl group is an important moiety for SOD inhibition as it invades a small hydrophobic cleft formed by the side chains of Lys-30 and Glu-100 disrupting the proper conformation of the allosteric site. The 2-pyridiyl group of our tested thiazole ligand was found to similarly invade this pocket and rests comfortably within appropriate distance with their hydrophobic side chains (Figure 3).

To assess the importance of different structural moieties of the thiazole derivative, a small set of virtual analogues of the tested pyridylthiazole with either oversized groups or truncated (smaller) functional groups were created. The bulkier virtual compound created by replacement of the 5-acetyl with pivaloyl
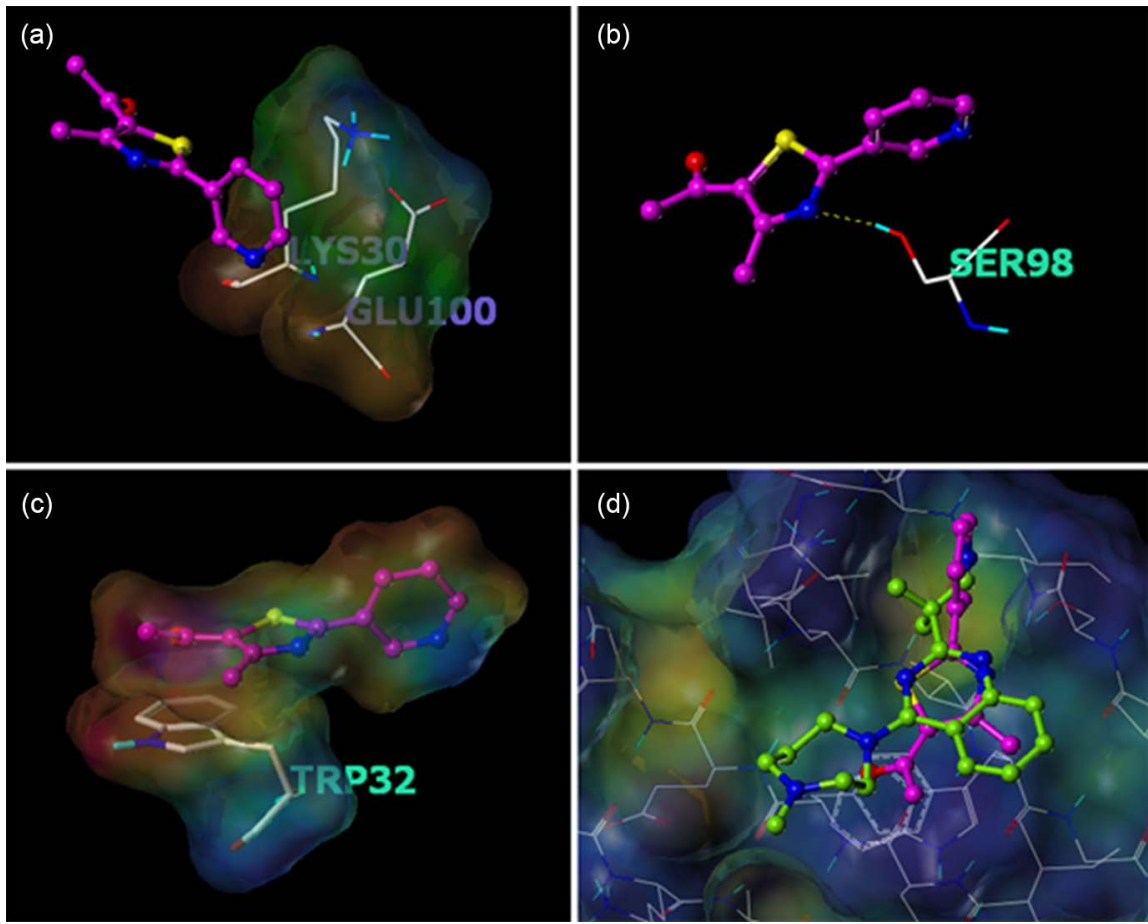

Figure 3. (a) Interactions of the thiazole compound with the hydrophobic cleft of Lys30 and Glu100. (b) Hydrogen bonding with the sidechain of Ser98. (c) $\pi-\pi$ interactions between the thiazole compound and Trp32. (d) Overlay of the thiazole compound and the co-crystallized quinazoline inhibitor of SOD. 
(trimethylacetyl) homologue, it showed lower scoring than our tested thiazole as the t-butyl group forced the thiazole ring away from making any significant aromatic interaction with Trp-32 and prevented the thiazole ring from making any hydrogen bonding with Ser-98. The only remaining binding interactions of the pyridine ring were with the small pocket between Lys-30 and Glu-100.

A smaller analogue without the pyridine ring was virtually constructed and included in the docking experiment to investigate the impact of the pyridyl group on binding. This compound hadrotated to place the acetyl group in the Lys30-Glu100 pocket but hydrophobic contacts appear to be less significant than that of the parent pyridyl analogue. Interestingly, the thiazole ring preferred to tighten its $\pi-\pi$ stacking attraction with Trp-32 making a hydrogen bond with Ser-89 (Figure 4). We conclude from this docking experiment that the tested thiazole analogue has optimum structural architecture to bind and inhibit superoxide dismutase enzyme.

Cytochrome P-450 2A6 (CYP2A6) gene is one of three members of CYP2A gene subfamily in human, CYP2A7 and CYP2A13. Their transcripts (CYP2A6, CYP2A7 and CYP2A13) have been found in liver although CYP2A6 is the most abundant form [31]. CYP2A6 utilizes a heme cofactor to oxidize its substrates and the active site of this enzyme is compact containing a hydrophobic Phe-cluster formed by the residues Phe107, Phe111, Phe108, Phe209 and Phe480. In this region, coumarin substrate is directed towards a regioselective oxidation site through the only hydrogen bond donor Asn297 [42].

Molecular docking against CYP2A6 revealed that tested thiazole analogue could bind to the (CYP2A6) in a similar fashion to the one observed in the 3-pyridyl-furan inhibitor co-crystallized with enzyme [43].

As shown in (Figure 5) the carbonyl oxygen of tested thiazole analogue occupies virtually the same position as the methanamino nitrogen of the bound inhibitor, effectively completing the coordination shell of the heme iron. The central thiazole moiety parallels the furan moiety of the inhibitor, which allows for the optimal positioning of the pyridyl moiety, thereby establishing a key hydrogen bond to the side chain of Asn297 and two edge-to-face interactions with the aromatic side chains of Phe107 and Phe111.
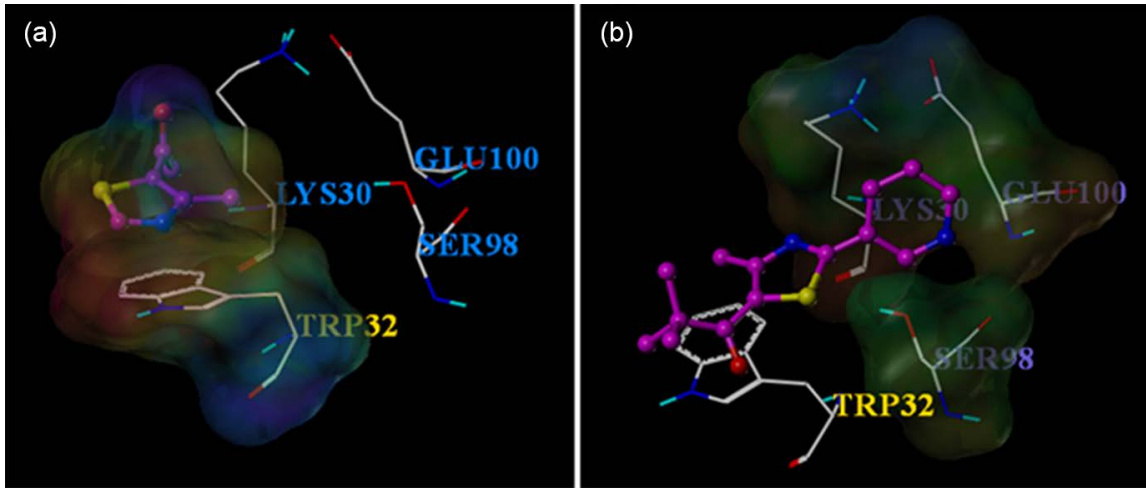

Figure 4. Binding mode of a bulkier analogue of the thiazole compound (a) and a truncated analogue lacking the pyridyl moiety (b) with SOD. 
To assess the importance of structural characteristics of the tested thiazole for the inhibition of CYP2A6, the same subset tested against SOD was once more tested against CYP2A6. The bulkier analogue possessing a tert-butyl group instead of methyl scored much lower. This is due to loss of essential interactions between the carbonyl oxygen and the metal ion and the hydrogen bond with Asn297. Hydrophobic interactions were rather maintained with the Phe cluster of CYP2A6. The smaller analogue lacking the pyridyl moiety also scored less due to loss of hydrophobic interactions with the Phe cluster and hydrogen bonding with Asn297. Interaction of the carbonyl oxygen with the metal ion was conserved. These findings indicate that the tested thiazole compound exhibits structural features necessary for the inhibition of CYP2A6 (Figure 6).
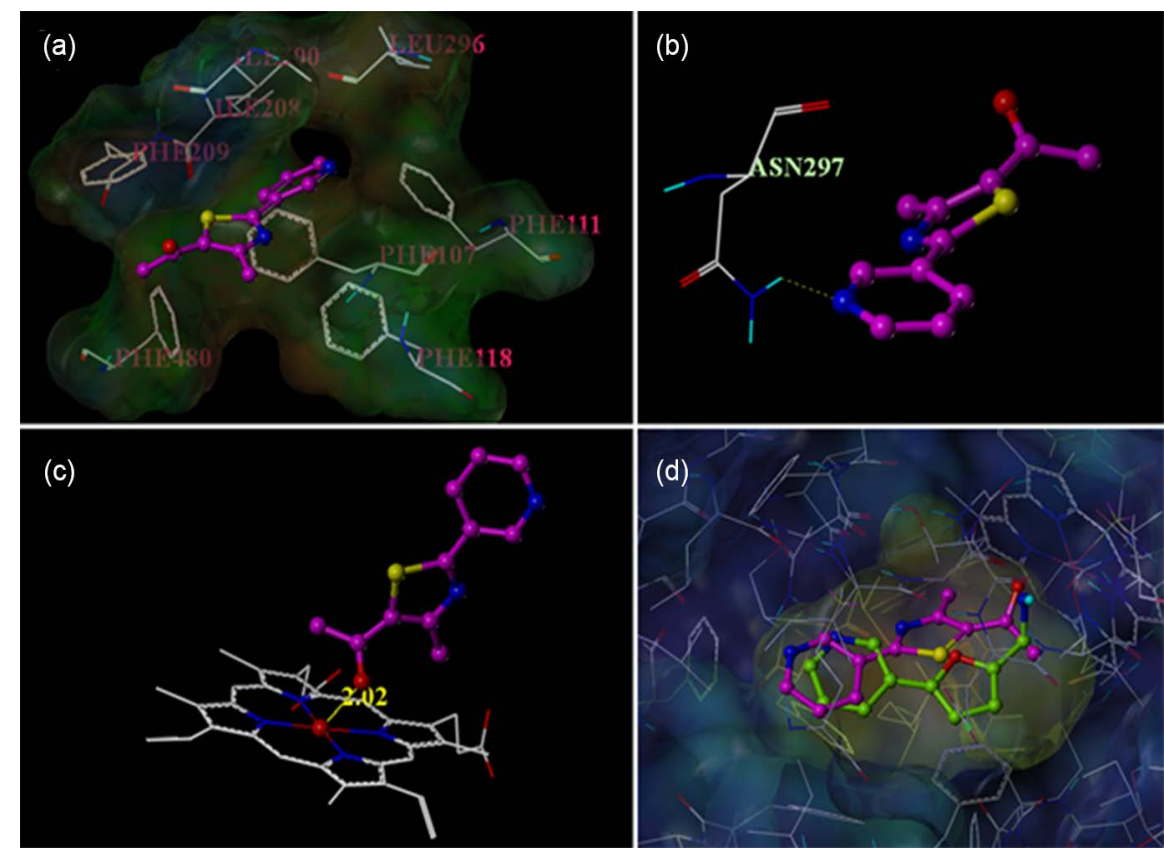

Figure 5. (a) Interactions of the thiazole compound with the hydrophobic Phe cluster of CYP2A6. (b) Hydrogen bonding with the side chain of Asn297. (c) Ineraction with the metal cation inside the heme cofactor of CYP2A6. (d) Overlay of the thiazole compound and the co-crystallized ligand of CYP2A6.
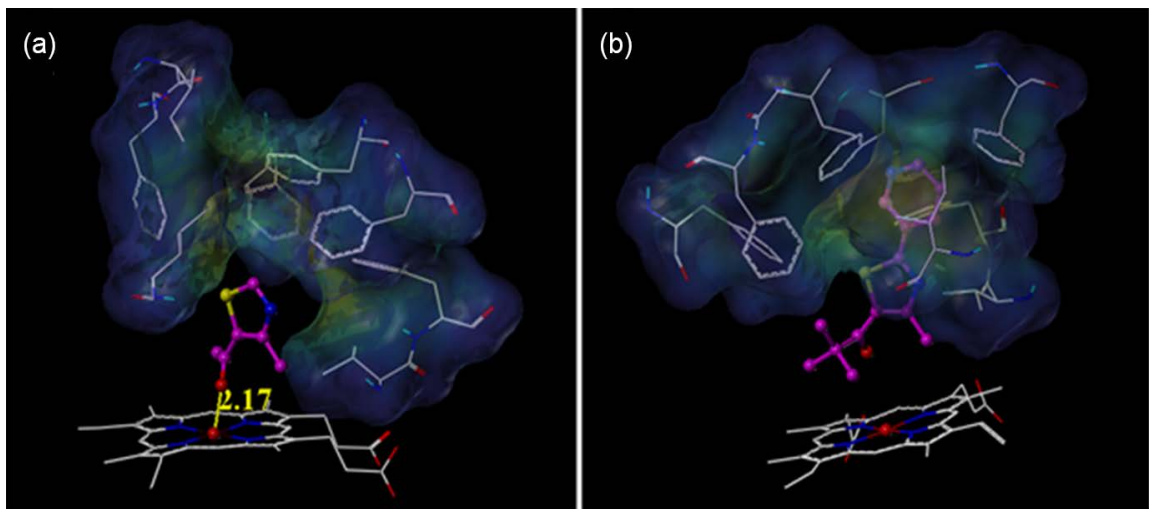

Figure 6. Binding mode of a bulkier analogue of the thiazole compound (a) and a truncated analogue lacking the pyridyl moiety (b) with CYP2A6. 
Overall, tested thiazole analogue can be accommodated in the CYP2A6 binding site and maintain key residue interactions consistent with the reported inhibitors, this suggests that tested thiazole analogue could exert its action via inhibition of CYP2A6. CYP2A6 inhibition will contributeto programmed cancer cell death and increased sensitivity to chemotherapy in hepatocellular carcinoma [31].

\section{Conclusion}

In conclusion, this study is reporting the selective antiproliferative activity of 5-acetyl-4-methyl-2-(3-pyridyl) thiazole in vitro and its possible mechanism of activity was demonstrated using docking studies. We also explained the structural determinants required for the simultaneous inhibition of SOD and CYP2A6 by conducting molecular comparisons in silico. The ability of the tested thiazole analogue to inhibit both SOD and CYP2A6 (mainly found in liver) might explain its pronounced activity as an anti-proliferative agent in liver carcinoma and the importance of inhibiting both enzymes simultaneously. Our findings may be useful in the future development of more potent cytotoxic agents directed towards liver cancer that act as adual inhibitors of SOD and CYP2A6.

\section{Acknowledgements}

We would like to acknowledge Dr. Andrew Flaus and Professor Heinz Peter Nasheuer from Center for Chromosome Biology, National University of Ireland for their help in editing this article.

\section{Conflict of Interest}

No conflict of interest associated with this work.

\section{References}

[1] Gibbs, J.B. (2000) Mechanism-Based Target Identification and Drug Discovery in Cancer Research. Science, 287, 1969-1973. https://doi.org/10.1126/science.287.5460.1969

[2] Cragg, G.M., Grothaus, P.G. and Newman, D.J. (2009) Impact of Natural Products on Developing New Anti-Cancer Agents. Chemical Reviews, 109, 3012-3043. https://doi.org/10.1021/cr900019j

[3] McFadyen, M.C., Melvin, W.T. and Murray, G.I. (2004) Cytochrome P450 Enzymes: Novel Options for Cancer Therapeutics. Molecular Cancer Therapeutics, 3 , 363-371.

[4] Otyepka, M., Skopalik, J., Anzenbacherova, E. and Anzenbacher, P. (2007) What Common Structural Features and Variations of Mammalian P450s Are Known to Date? Biochimica et Biophysica Acta, 1770, 376-389. https://doi.org/10.1016/j.bbagen.2006.09.013

[5] Yano, J.K., Denton, T.T., Cerny, M.A., Zhang, X., Johnson, E.F. and Cashman, J.R. (2006) Synthetic Inhibitors of Cytochrome P-450 2A6: Inhibitory Activity, Difference Spectra, Mechanism of Inhibition, and Protein Cocrystallization. Journal of 
Medicinal Chemistry, 49, 6987-7001. https://doi.org/10.1021/jm060519r

[6] Yano, J.K., Hsu, M.H., Griffin, K.J., Stout, C.D. and Johnson, E.F. (2005) Structures of Human Microsomal Cytochrome P450 2A6 Complexed with Coumarin and Methoxsalen. Nature structural \& Molecular Biology, 12, 822-823.

https://doi.org/10.1038/nsmb971

[7] Hoffman, S.M., Nelson, D.R. and Keeney, D.S. (2001) Organization, Structure and Evolution of the CYP2 Gene Cluster on Human Chromosome 19. Pharmacogenetics, 11, 687-698. https://doi.org/10.1097/00008571-200111000-00007

[8] Ioannides, C. (2008) Cytochromes P450: Role in the Metabolism and Toxicity of Drugs and Other Xenobiotics. Royal Society of Chemistry, London.

[9] Abu-Bakar, A., Arthur, D.M., Wikman, A.S., Rahnasto, M., Juvonen, R.O., Vepsalainen, J., Raunio, H., Ng, J.C. and Lang, M.A. (2012) Metabolism of Bilirubin by Human Cytochrome P450 2A6. Toxicology and Applied Pharmacology, 261, 50-58. https://doi.org/10.1016/j.taap.2012.03.010

[10] Raunio, H., Juvonen, R., Pasanen, M., Pelkonen, O., Paakko, P. and Soini, Y. (1998) Cytochrome P4502A6 (CYP2A6) Expression in Human Hepatocellular Carcinoma. Hepatology, 27, 427-432. https://doi.org/10.1002/hep.510270217

[11] Nakajima, M., Itoh, M., Sakai, H., Fukami, T., Katoh, M., Yamazaki, H., Kadlubar, F.F., Imaoka, S., Funae, Y. and Yokoi, T. (2006) CYP2A13 Expressed in Human Bladder Metabolically Activates 4-Aminobiphenyl. International Journal of Cancer, 119, 2520-2526. https://doi.org/10.1002/ijc.22136

[12] McCord, J.M. and Fridovich, I. (1969) Superoxide Dismutase. An Enzymic Function for Erythrocuprein (Hemocuprein). The Journal of Biological Chemistry, 244, 6049-6055.

[13] Hough, M.A. and Hasnain, S.S. (1999) Crystallographic Structures of Bovine Copper-Zinc Superoxide Dismutase Reveal Asymmetry in Two Subunits: Functionally Important Three and Five Coordinate Copper Sites Captured in the Same Crystal. Journal of Molecular Biology, 287, 579-592.

https://doi.org/10.1006/jmbi.1999.2610

[14] Strange, R.W., Hough, M.A., Antonyuk, S.V. and Hasnain, S.S. (2012) Structural Evidence for a Copper-Bound Carbonate Intermediate in the Peroxidase and Dismutase Activities of Superoxide Dismutase. PLoS ONE, 7, e44811. https://doi.org/10.1371/journal.pone.0044811

[15] Bordo, D., Pesce, A., Bolognesi, M., Elena Stroppolo, M., Falconi, M. and Desideri, A. (2001) Copper-Zinc Superoxide Dismutase in Prokaryotes and Eukaryotes. In: Messerschmidt, A., Huber, R., Wieghardt, K. and Poulos, T., Eds., Handbook of Metalloproteins, John Wiley \& Sons, Hoboken, 6.

[16] Banci, L., Bertini, I., Cramaro, F., Del Conte, R. and Viezzoli, M.S. (2002) The Solution Structure of Reduced Dimeric Copper Zinc Superoxide Dismutase. The Structural Effects of Dimerization. European Journal of Biochemistry/ FEBS, 269, 1905 1915. https://doi.org/10.1046/j.1432-1033.2002.02840.x

[17] Sharma, R.N., Xavier, F.P., Vasu, K.K., Chaturvedi, S.C. and Pancholi, S.S. (2009) Synthesis of 4-Benzyl-1,3-Thiazole Derivatives as Potential Anti-Inflammatory Agents: An Analogue-Based Drug Design Approach. Journal of Enzyme Inhibition and Medicinal Chemistry, 24, 890-897. https://doi.org/10.1080/14756360802519558

[18] Medan, D., Wang, L., Toledo, D., Lu, B., Stehlik, C., Jiang, B.H., Shi, X. and Rojanasakul, Y. (2005) Regulation of Fas (CD95)-Induced Apoptotic and Necrotic Cell Death by Reactive Oxygen Species in Macrophages. Journal of Cellular Physiology, 203, 78-84. https://doi.org/10.1002/jcp.20201 
[19] Krchnak, V. and Holladay, M.W. (2002) Solid Phase Heterocyclic Chemistry. Chemical Reviews, 102, 61-91. https://doi.org/10.1021/cr010123h

[20] Carter, J.S., Kramer, S., Talley, J.J., Penning, T., Collins, P., Graneto, M.J., Seibert, K., Koboldt, C.M., Masferrer, J. and Zweifel, B. (1999) Synthesis and Activity of Sulfonamide-Substituted 4,5-Diaryl Thiazoles as Selective Cyclooxygenase-2 Inhibitors. Bioorganic \& Medicinal Chemistry Letters, 9, 1171-1174. https://doi.org/10.1016/S0960-894X(99)00157-2

[21] Bell, F.W., Cantrell, A.S., Hogberg, M., Jaskunas, S.R., Johansson, N.G., Jordan, C.L., Kinnick, M.D., Lind, P., Morin, J.M., Jr., Noreen, R., et al. (1995) Phenethylthiazolethiourea (PETT) Compounds, a New Class of HIV-1 Reverse Transcriptase Inhibitors. 1. Synthesis and Basic Structure-Activity Relationship Studies of PETT Analogs. Journal of Medicinal Chemistry, 38, 4929-4936. https://doi.org/10.1021/jm00025a010

[22] Desai, N.C., Rajpara, K.M., Joshi, V.V., Vaghani, H.V. and Satodiya, H.M. (2012) Synthesis and Characterization of Some New Thiazole Based Thiazolidinone Derivatives as Potent Antimicrobial and Antimycobacterial Agents. Anti-Infective Agents, 10, 75-86. https://doi.org/10.2174/2211362611208020075

[23] Jisha, M., Kamalabhai, A., Babu, G. and Biju, C. (2013) Synthesis, Characterization and in Vitro Anticancer Screening of Novel Thiazole-1, 3, 4-Oxadiazole Hybrid Analogues. Journal of Chemical and Pharmaceutical Research, 5, 64-70.

[24] Rudolph, J., Theis, H., Hanke, R., Endermann, R., Johannsen, L. and Geschke, F. (2001) Seco-Cyclothialidines: New Concise Synthesis, Inhibitory Activity toward Bacterial and Human DNA Topoisomerases, and Antibacterial Properties. Journal of Medicinal Chemistry, 44, 619-626. https://doi.org/10.1021/jm0010623

[25] Radhakrishnan, S.K., Bhat, U.G., Hughes, D.E., Wang, I.C., Costa, R.H. and Gartel, A.L. (2006) Identification of a Chemical Inhibitor of the Oncogenic Transcription Factor Forkhead Box M1. Cancer Research, 66, 9731-9735. https://doi.org/10.1158/0008-5472.CAN-06-1576

[26] Bhat, U.G., Zipfel, P.A., Tyler, D.S. and Gartel, A.L. (2008) Novel Anticancer Compounds Induce Apoptosis in Melanoma Cells. Cell Cycle, 7, 1851-1855. https://doi.org/10.4161/cc.7.12.6032

[27] Chang, S., Zhang, Z., Zhuang, X., Luo, J., Cao, X., Li, H., Tu, Z., Lu, X., Ren, X. and Ding, K. (2012) New Thiazolecarboxamides as Potent Inhibitors of Akt Kinases. Bioorganic \& Medicinal Chemistry Letters, 22, 1208-1212. https://doi.org/10.1016/j.bmcl.2011.11.080

[28] Bondock, S., Naser, T. and Ammar, Y.A. (2013) Synthesis of Some New 2-(3-pyridyl)-4,5-disubstituted Thiazoles as Potent Antimicrobial Agents. European Journal of Medicinal Chemistry, 62, 270-279. https://doi.org/10.1016/j.ejmech.2012.12.050

[29] Skehan, P., Storeng, R., Scudiero, D., Monks, A., McMahon, J., Vistica, D., Warren, J.T., Bokesch, H., Kenney, S. and Boyd, M.R. (1990) New Colorimetric Cytotoxicity Assay for Anticancer-Drug Screening. Journal of the National Cancer Institute, 82, 1107-1112. https://doi.org/10.1093/jnci/82.13.1107

[30] Kershaw, N.M., Wright, G.S., Sharma, R., Antonyuk, S.V., Strange, R.W., Berry, N.G., O’Neill, P.M. and Hasnain, S.S. (2013) X-Ray Crystallography and Computational Docking for the Detection and Development of Protein-Ligand Interactions. Current Medicinal Chemistry, 20, 569-575.

[31] Pelkonen, O., Rautio, A., Raunio, H. and Pasanen, M. (2000) CYP2A6: A Human Coumarin 7-Hydroxylase. Toxicology, 144, 139-147. https://doi.org/10.1016/S0300-483X(99)00200-0 
[32] Fridovich, I. (1995) Superoxide Radical and Superoxide Dismutases. Annual Review of Biochemistry, 64, 97-112. https://doi.org/10.1146/annurev.bi.64.070195.000525

[33] Marklund, S.L., Westman, N.G., Lundgren, E. and Roos, G. (1982) Copper- and Zinc-Containing Superoxide Dismutase, Manganese-Containing Superoxide Dismutase, Catalase, and Glutathione Peroxidase in Normal and Neoplastic Human Cell Lines and Normal Human Tissues. Cancer Research, 42, 1955-1961.

[34] Shulyakovskaya, T., Sumegi, L. and Gal, D. (1993) In Vivo Experimental Studies on the Role of Free Radicals in Photodynamic Therapy. I. Measurement of the Steady State Concentration of Free Radicals in Tumor Tissues of Mice. Biochemical and Biophysical Research Communications, 195, 581-587. https://doi.org/10.1006/bbrc.1993.2085

[35] Van Driel, B.E. and Van Noorden, C.J. (1999) Oxygen Insensitivity of the Histochemical Assay of Glucose-6-Phosphate Dehydrogenase Activity for the Discrimination between Nonmalignant and Malignant Cells. The Journal of Histochemistry and Cytochemistry, 47, 575-582. https://doi.org/10.1177/002215549904700501

[36] Marzo, I., Brenner, C., Zamzami, N., Jürgensmeier, J.M., Susin, S.A., Vieira, H.L., Prévost, M.-C., Xie, Z., Matsuyama, S. and Reed, J.C. (1998) Bax and Adenine Nucleotide Translocator Cooperate in the Mitochondrial Control of Apoptosis. Science, 281, 2027-2031. https://doi.org/10.1126/science.281.5385.2027

[37] Vander Heiden, M.G., Chandel, N.S., Williamson, E.K., Schumacker, P.T. and Thompson, C.B. (1997) Bcl-xL Regulates the Membrane Potential and Volume Homeostasis of Mitochondria. Cell, 91, 627-637. https://doi.org/10.1016/S0092-8674(00)80450-X

[38] Li, P., Nijhawan, D., Budihardjo, I., Srinivasula, S.M., Ahmad, M., Alnemri, E.S. and Wang, X. (1997) Cytochrome $c$ and dATP-Dependent Formation of Apaf-1/Caspase-9 Complex Initiates an Apoptotic Protease Cascade. Cell, 91, 479-489. https://doi.org/10.1016/S0092-8674(00)80434-1

[39] D’Amato, R.J., Lin, C.M., Flynn, E., Folkman, J. and Hamel, E. (1994) 2-Methoxyestradiol, an Endogenous Mammalian Metabolite, Inhibits Tubulin Polymerization by Interacting at the Colchicine Site. Proceedings of the National Academy of Sciences of the United States of America, 91, 3964-3968. https://doi.org/10.1073/pnas.91.9.3964

[40] Fotsis, T., Zhang, Y., Pepper, M.S., Adlercreutz, H., Montesano, R., Nawroth, P.P. and Schweigerer, L. (1994) The Endogenous Oestrogen Metabolite 2-Methoxyoestradiol Inhibits Angiogenesis and Suppresses Tumour Growth. Nature, 368, $237-$ 239. https://doi.org/10.1038/368237a0

[41] Antonyuk, S., Strange, R.W. and Hasnain, S.S. (2010) Structural Discovery of Small Molecule Binding Sites in Cu-Zn Human Superoxide Dismutase Familial Amyotrophic Lateral Sclerosis Mutants Provides Insights for Lead Optimization. Journal of Medicinal Chemistry, 53, 1402-1406. https://doi.org/10.1021/jm9017948

[42] Kim, D., Wu, Z.L. and Guengerich, F.P. (2005) Analysis of Coumarin 7-Hydroxylation Activity of Cytochrome P450 2A6 Using Random Mutagenesis. The Journal of Biological Chemistry, 280, 40319-40327. https://doi.org/10.1074/jbc.M508171200

[43] Khojasteh-Bakht, S.C., Koenigs, L.L., Peter, R.M., Trager, W.F. and Nelson, S.D. (1998) (R)-(+)-Menthofuran Is a Potent, Mechanism-Based Inactivator of Human Liver Cytochrome P450 2A6. Drug Metabolism and Disposition: The Biological Fate of Chemicals, 26, 701-704. 
Submit or recommend next manuscript to SCIRP and we will provide best service for you:

Accepting pre-submission inquiries through Email, Facebook, LinkedIn, Twitter, etc. A wide selection of journals (inclusive of 9 subjects, more than 200 journals)

Providing 24-hour high-quality service

User-friendly online submission system

Fair and swift peer-review system

Efficient typesetting and proofreading procedure

Display of the result of downloads and visits, as well as the number of cited articles Maximum dissemination of your research work

Submit your manuscript at: http://papersubmission.scirp.org/

Or contact abc@scirp.org 